Introduction Electronic cigarettes (EC) are currently the preferred nicotine replacement product to support tobacco smoking quit attempts. Despite the potential harm reduction associated with EC, their use remains controversial. The aim of this study was to evaluate doctors' knowledge and perceptions of NRT and EC.

Methods An online and paper survey was distributed to healthcare professionals working within NHS Greater Glasgow and Clyde from 3rd to 19th October 2017.

Results 2291 healthcare professionals completed the survey of which 338 were completed by doctors and were included in this analysis. Out of these, 83.2\% $(n=281)$ regularly see patients who smoke tobacco cigarettes. When asked the question 'Do you think EC are a good thing?', 30.2\% $(n=102)$ disagreed; $31.3 \% \quad(n=106)$ agreed and $38.5 \% \quad(n=130)$ remained neutral. The majority of doctors perceived that nicotine replacement patches (NRP) and EC were less harmful in comparison to tobacco smoking (NRP 97.3\%, $\mathrm{n}=329$; $\mathrm{EC}$ $83.4 \%, \mathrm{n}=282) .53 .3 \%(\mathrm{n}=180)$ of doctors said they would recommend EC as a method to stop smoking, while $46.7 \%$ $(n=158)$ would not. $65.5 \%(n=222)$ of doctors agreed that they did not feel confident about advising patients regarding EC use and $76.1 \% \quad(n=257)$ felt that they required more information and guidance.

Conclusions Whilst the majority of doctors perceived EC as a safer alternative to tobacco smoking there is a discrepancy between their perceptions and what they would clinically recommend to patients. Our data highlight that in the context of smoking cessation and the unknown long-term health effects from EC exposure, doctors may benefit from having access to medical evidence and latest recommendations regarding EC.

\section{CHOLESTEROL CRYSTAL SECRETION OF IL-1 $\beta$ FROM PBMCS IS REDUCED WITH SIMVASTATIN TREATMENT}

${ }^{1} \mathrm{~N}$ Gangadharan, ${ }^{1} \mathrm{P}$ Kavanagh, ${ }^{2} \mathrm{PT}$ Wash, 'L Hemeryck, 'I Kieran, 'M Barry, ${ }^{1} \mathrm{M}$ Lucitt. ${ }^{1}$ Pharmacology and Therapeutics, Trinity College Dublin, Dublin, Ireland; ${ }^{2}$ Clinical Medicine, Trinity College Dublin, Dublin, Ireland

\subsection{6/heartjnl-2018-SCF.12}

Considerable evidence implicates a role for interleukin-1 beta (IL-1 $\beta)$ in the pathogenesis of atherosclerosis ${ }^{1}$ revealing its potential as a novel therapeutic target. Statins are known to have anti-inflammatory effects, ${ }^{2}$ however the specific mechanisms remain to be established. To test the anti-inflammatory effects of simvastatin, PBMCs were isolated from healthy donors and treated in vitro with simvastatin $(100 \mu \mathrm{M})$ or from hyperlipidaemic patients at baseline and following 8 weeks simvastatin (10-20 mg) daily treatment. PBMCs were then stimulated with LPS $(100 \mathrm{ng} / \mathrm{ml})$ for 3 hour followed by cholesterol crystal (CC) $(1 \mathrm{mg} / \mathrm{ml})$ stimulation overnight to activate the NLRP3 inflammasome complex involved in processing IL-1 $\beta$ to its mature secreted form. IL-I $\beta$ levels in the supernatants form PBMCs was measured by ELISA. All experiments carried out were approved by the Medical Research Ethics Committees at St James Hospital/AMNCH, Dublin 8, Ireland and comply fully with the Declaration of Helsinki. Patients $(\mathrm{n}=9)$ taking simvastatin $(10-20 \mathrm{mg}$ daily) over 8 weeks exhibited reduced LDL cholesterol, $(4.87 \pm 0.76 \mathrm{mmol} / \mathrm{L})$ pre vs $(3.78 \pm 0.67 \mathrm{mmol} / \mathrm{L})$ post statin treatment. Simvastatin treatment also reduced levels of IL-1 $\beta$ secretion by PBMCs, when stimulated with LPS and CC, $(5.27 \pm 0.6 \mathrm{ng} / \mathrm{ml})$ pre vs $(4.27 \pm 0.5 \mathrm{ng} / \mathrm{ml})$ post statin treatment. Similarly, in vitro treatment of PBMCs with simvastatin $(100 \mu \mathrm{M})$ reduced IL-1 $\beta$ secretion upon activation with LPS and CC, $(2.37 \pm 0.17 \mathrm{ng} /$ $\mathrm{ml})$ control vs $(0.64 \pm 0.06 \mathrm{ng} / \mathrm{ml})$ simvastatin treatment. Values presented are mean \pm sem. We have demonstrated that CC induced IL-1 $\beta$ release by PBMCs from hyperlipidaemic patients, is reduced after treatment with simvastatin. These data identify a previously unappreciated beneficial role for statin therapy in atherosclerotic patients.

\section{REFERENCES}

1. Duewell P, et al. Nature 2010;464:1357-61.

2. Arslan F, et al. Circ Res 2008;103:334-6.

\section{RED YEAST RICE EXTRACT REDUCES IL-1 $\beta$ SECRETION FROM PBMCS WHEN TREATED WITH CHOLESTEROL CRYSTALS}

${ }^{1} \mathrm{PV}$ Kavanagh, ${ }^{2} \mathrm{PT}$ Walsh, ${ }^{1} \mathrm{M}$ Lucitt. ${ }^{1}$ Pharmacology and Therapeutics, Trinity College Dublin, Dublin, Ireland; ${ }^{2}$ Clinical Medicine, Trinity College Dublin, Dublin, Ireland

10.1136/heartjnl-2018-SCF.13

Red yeast rice (RYR) nutraceutical contains monacolin $\mathrm{K}$, a natural occurring statin. ${ }^{1}$ Here we compare lovastatin and simvastatin effects on interleukin-1 beta (IL-1ß) levels to that of extracts from a RYR product. Standard curves using $0.375-$ $24 \mu \mathrm{g} / \mathrm{mL}$ of lovastatin pre and post hydrolysis with $\mathrm{NaOH}$ were constructed using liquid chromatography-mass spectrometry (LC-MS), operated with selected ion monitoring (SIM) and a $\mathrm{m} / \mathrm{z}$ of 427 to detect the lactone and $\mathrm{m} / \mathrm{z}$ of 445 to detect the hydroxyl acid forms of lovastatin. RYR, $0.22 \mu \mathrm{m}$ filtered ethanol extractions pre and post hydrolysis were analysed by LC-MS for monacolin $\mathrm{k}$ lactone (inactive) and hydroxyl acid (active) forms and quantified from the standard curves generated above. Human PBMCs treated in vitro with lovastatin $(100 \mu \mathrm{M})$, simvastatin $(100 \mu \mathrm{M})$ or RYR extracts $(9 \mu \mathrm{g} / \mathrm{ml}$, $18 \mu \mathrm{g} / \mathrm{ml})$, stimulated with LPS $(100 \mathrm{ng} / \mathrm{ml})$ for 3 hours, followed by cholesterol crystals (CC) $(1 \mathrm{mg} / \mathrm{ml})$ stimulation overnight to induce secretion of IL-I $\beta$, was subsequently measured by ELISA. Data shown as mean \pm S.E.M, $n=3$. Extracts from $9 \mathrm{~g}$ of RYR (3 capsules) analysed by LC-MS detected 1.86$2.43 \mathrm{mg} /$ capsule of the lactone. Extract levels of monacolin $\mathrm{K}$ lactone to monacolin $\mathrm{K}$ hydroxyl acid, pre and post hydrolysis was determined, (15:1) pre and (1:2) post hydrolysis. PBMCs treated with lovastatin or simvastatin reduced secreted levels of IL-1 $\beta,(0.99 \pm 0.05 \mathrm{ng} / \mathrm{ml})$ lovastatin, $(1.75 \pm 0.14 \mathrm{ng} / \mathrm{ml}) \mathrm{sim}$ vastatin vs $(2.6 \pm 0.47 \mathrm{ng} / \mathrm{ml})$ LPS and CC treatment alone. Similarly, in vitro treatment of PBMCs with RYR extracts also reduced IL-1 $\beta$ secretion, $(1.15 \pm 0.09 \mathrm{ng} / \mathrm{ml}) \mathrm{RYR} 18 \mu \mathrm{g} / \mathrm{ml}$ and $(1.49 \pm 0.28 \mathrm{ng} / \mathrm{ml}) \mathrm{RYR} 9 \mu \mathrm{g} / \mathrm{ml}$ vs $(2.6 \pm 0.47 \mathrm{ng} / \mathrm{ml})$ LPS and CC treatment alone. LPS and CC induced IL-1 $\beta$ release from PBMCs is reduced when treated with RYR extracts and is comparable to IL-1 $\beta$ release effects seen with prescription statins. These data identify a previously unappreciated antiinflammatory effect of RYR supplements.

\section{REFERENCE}

1. Zhao SP, et al. Circulation 2004;110:915-920. 